\title{
Phenolic content as an indicator of resistance of cowpea seedlings to Sclerotium rolfsii
}

\author{
Appolinaire Adandonon*1,2; Thierry Regnier ${ }^{3}$ and Theresa AS Aveling ${ }^{2}$ \\ ${ }^{1 *}$ Correspondence: School of Crop and Seed Production and Management, University of Agriculture of Kétou, \\ 08 BP 1055 Cotonou, Republic of Benin; Tél. 0022920253331 e.mail: adanappo@yahoo.fr \\ ${ }^{2}$ Department of Plant and Soil Sciences, Forestry and Agricultural Biotechnology Institute, University of \\ Pretoria, Pretoria 0002, South Africa. \\ ${ }^{3}$ Department of Biotechnology and Food Technology, Tshwane University of Technology, Pretoria 0001, South \\ Africa.
}

\begin{abstract}
The role of phenolics in plant tolerance to pathogen infection is well documented. The objective of the present preliminary investigation was to study phenolic metabolites involved in the tolerance or susceptibility of cowpea (Vigna unguiculata Walp.) cultivars to Sclerotium rolfsii Sacc. and to use their presence as a possible screening tool. Total, free acid, ester-bound and cell wall-bound phenolics of 10 cowpea cultivars were quantified. In healthy seedlings, the tolerant cultivars displayed the higher phenol content than the susceptible cultivars. In S. rolfsii infected seedlings, the highest increase was found from $48 \mathrm{~h}$ after inoculation. The net effect of inoculation was a $630 \%$ increase in total phenolics (soluble and insoluble) in the stem of tolerant cultivars while the total phenolic content increased only by $212 \%$ in the stems of susceptible cultivars. Two phytoalexins were detected. Although, no significant difference $(P=0.05)$ was detected among cultivars, in terms of free acid phenolics, the amount of ester-bound and cell wall-bound phenolics significantly increased, therefore demonstrating a similar trend to the one observed for the total phenolic content. These preliminary results showed that the presence of phenolics before and after $S$. rolfsii infection may be used as a rapid screening method for detection of tolerance to $S$. rolfsii damping-off and stem rot of cowpea.
\end{abstract}

Keywords: Cinnamic acids, phenolics, phytoalexin, resistance, Sclerotium, Vigna unguiculata. 
Sclerotium rolfsii Sacc. is one of the devastating soil-borne pathogens with a wide host range causing diseases in several monocot and dicot plants (Maurya et al. 2007). In a field trial in the Ouémé valley in the Republic of Benin, variation in susceptibility among cowpea cultivars to $S$. rolfsii was detected and some were more tolerant producing higher yields than others (Adandonon et al. 2005a). Jain et al. (2011) indicated that phenols are induced in most of the plant tissues undergoing tolerance responses due to non-host pathogen interaction, or undergoing defensive responses due to beneficial microorganism actions. Lignin for instance and its phenolic precursors are themselves toxic to pathogens (Basha et al. 2006) and their polymerization makes cell walls thicker and stronger, which restricts penetration of cell wall by virulent pathogens. Moreover, it was discovered that dark coloured seeds tend to be more tolerant to fungal attack and storage fungi compared to white or cream coloured seeds (Kritzinger et al. 2002). Brown cowpea seeds, containing a higher concentration of soluble phenolics, mainly flavonoids, were found to be more tolerant to Colletotrichum dematium (Pers. Ex Fr) Grove (Pakela 2003) and damping-off (Aveling and Powell 2005) than white or cream cultivars. To our knowledge, although the tolerance mechanism involving an increase in phenolic compounds or/and production of phytoalexins (Morrissey and Osbourn 1999) is well documented, little is known about the phenolic content of cowpea associated with tolerance or susceptibility to $S$. rolfsii infection. The objective of the present preliminary research was to study the phenolic compounds deployed during cowpea resistance/tolerance to $S$. rolfsii damping-off and stem rot and determine whether their presence could be used as a rapid screening method for detection of tolerance.

A virulent isolate of $S$. rolfsii (IITA 408, International Institute of Tropical Agriculture, Cotonou, Benin) and 10 cowpea cultivars with known tolerance or susceptibility to the pathogen (Adandonon et al. 2005b) were included in the study: Five tolerant, Cameroon, Kpodji, Gboto, Sèwé and Tchawé daho; two intermediate, IT83D-326-2 and 
Delekinwa and; three susceptible, TVU 72-74, KVX-61-1 and Tchawé kpayo. As a preliminary test, Tchawé kpayo (susceptible) and Cameroon (tolerant) were used to determine the time of phenolic induction in the stems of plants infected by S. rolfsii. All 10 cultivars were used in all subsequent experiments.

One 5-mm diameter disc of 4-d-old S. rolfsii culture on PDA was placed adjacent to wounded collar of 5-day old cowpea seedlings and incubated in the greenhouse at temperatures varying between 25 to $27{ }^{\circ} \mathrm{C}$. At $0,6,24,48$ and $72 \mathrm{~h}$ after inoculation, five seedlings $(\mathrm{N}=5)$, representing a replicate were uprooted and 6 -cm long stem samples were separately cut from the seedling collar upwards and three replicates of five seedlings each, were used. Samples were frozen in liquid nitrogen, ground into a fine powder using a mortar and pestle, placed in respective Eppendorf tubes and stored in the dark until further use. For the chemical analysis, all reagents and solvents used were of analytical grade (AR). Standards were purchased from Sigma-Aldrich (Steinheim, Germany) and the Folin-Ciocalteau reagent (FCR) was obtained from Merck (Dusseldorf, Germany). The total dry weight (DW) of each of the subsamples $(0.05 \mathrm{~g})$ was weighed into $1.5 \mathrm{ml}$ Eppendorf tubes. The samples were separately extracted with $1 \mathrm{ml}$ of methanol/acetone/water $(7: 7: 1 \mathrm{v} / \mathrm{v} / \mathrm{v})$ Extracts were centrifuged at $10^{4} \mathrm{~g}$ for $1 \mathrm{~min}$ in a microcentrifuge $7200 \mathrm{G}$ (Denver Instrumental Company, USA) and the supernatant was retained.

The amount of total soluble phenolic compounds from the 10 cultivars was determined colorimetrically (Du Plooy et al. 2009). Quantification of phenolics was carried out using a calibration curve of gallic acid and the cell wall-bound phenolic compounds determined following methods of Regnier (1994). The identification and quantification of the extract components from the 10 cultivars was conducted using Thin Layer Chromatography (TLC) The tolerant Cameroon cultivar was used for high-performance liquid chromatography (HPLC) analysis using a Hewlett Packard 1040 serie II HPLC with a normal one-wave length 
detector (three phases pump). A MALsil $\mathrm{C}_{18}, 5$-micron reverse-phase analytical column (250 $\mathrm{x} 46 \mathrm{~nm}, 5 \mu \mathrm{m}$ particle size, Chrompack, Separations, Johannesburg) was used together with a precolumn (4.0 mm ID, $150 \mathrm{~mm}$ long). Samples $(20 \mu \mathrm{l})$ were analysed using a gradient of two solvents ranging from $7 \%$ solvent A (acetonitrile, HPLC grade), $93 \%$ solvent B $(0.1 \%$ aqueous orthophosphoric acid, $\mathrm{pH} 2.6$ ) to $70 \%$ solvent $\mathrm{A}$, in $45 \mathrm{~min}$. The wavelengths of the detector were 280 and $320 \mathrm{~nm}$. The chromatogram was analysed with Hewlett Packard HPLC software (Star, Dos series). For statistical analysis, the general linear model (GLM) was used under SAS System and mean separations were done using the Student Newman Keuls option.

In the preliminary test used to determine the time of phenolic induction in the stems of plants infected by $S$. rolfsii, the total phenolic content did not differ significantly between inoculated and uninoculated plants of Tchawé kpayo (susceptible) until $24 \mathrm{~h}$ after inoculation, in contrast to Cameroon, the tolerant cultivar (Fig. 1). At 48 h, the total phenolic content in the inoculated Cameroon cultivar was significantly $(P<0.05)$, about three times, higher than that in the inoculated Tchawé kpayo cultivar. However, for both cultivars, the highest total phenolic content reached at $48 \mathrm{~h}$ in inoculated plants did not differ $(P=0.05)$ from that at 72 $\mathrm{h}$, indicating that the time of maximum total soluble phenolic induction in the cowpea cultivars after $S$. rolfsii infection is $48 \mathrm{~h}$ (Fig. 1).

Total phenolic (TP) extract results (Table 1) confirm that the 10 cowpea cultivars tested have a pre-existing total phenolic content that is equal to or more than $2.4 \mathrm{mg}$ gallic acid/g DW. The five tolerant cultivars, namely Cameroon, Kpodji, Gboto, Sèwé and Tchawé daho, had significantly higher $(P<0.05)$ pre-existing phenolic content than the susceptible cultivars. The results showed a significant difference $(P<0.05)$ among cultivars in terms of the total phenolic compound present in the stem cells $48 \mathrm{~h}$ after inoculation with $S$. rolfsii. Three significantly different $(P<0.05)$ groups were observed in terms of the total phenolic content (Table 1): the first group with total phenolic content greater than 19 mg gallic acid 

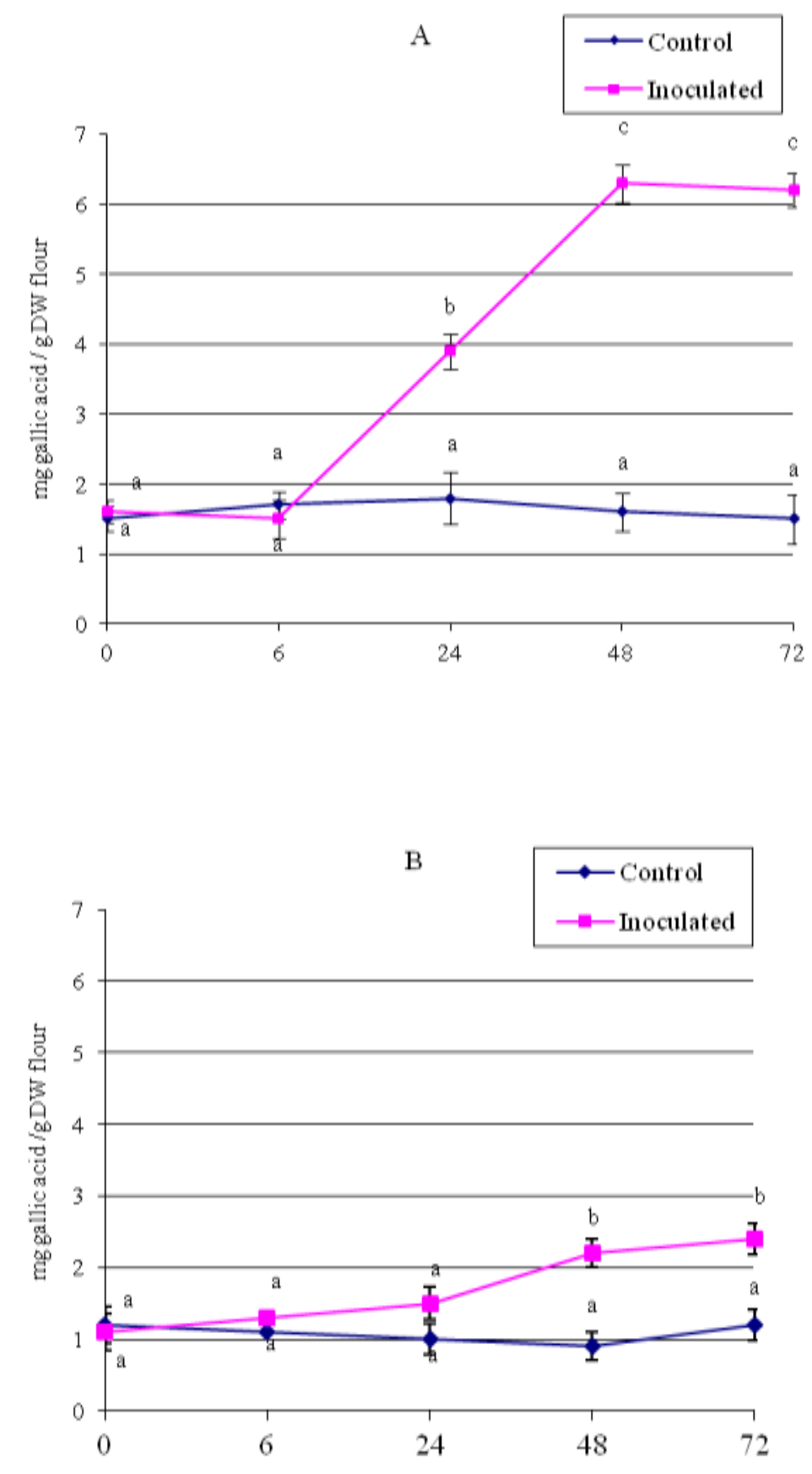

Time (h) after inoculation with $S$. rolfsii

Figure 1. Effect of time (h) after Sclerotium rolfsii infection, on maximum total soluble phenolic induction in two cowpea cultivars: A) Cameroon (tolerant); and B) Tchawé kpayo (susceptible). Within a figure line, values not followed by the same letters are significantly different $(P<0.05)$ according to the Student Newman Keuls option. For Figure 1A, LSD, $P$, and CV (\%) values are 2.1;0.037; and 7.5 when inoculated and 1.3; 0.34 and 5.2 when not inoculated. For Figure 1B, the values are 0.4; 0.025 and 5.7 when inoculated and $0.84 ; 0.26$ and 6.9 when not inoculated. Five-day old seedlings were inoculated using inoculum plug (of 4-day old culture of $S$. rolfsii on PDA) placed adjacent to each wounded seedling collar. Total soluble phenolics were determined at 0 , 6, 24, 48 and $72 \mathrm{~h}$ after inoculation. Controls were non-inoculated wounded seedlings. 
Table 1. Total phenolic compounds in the cells of cowpea seedlings $48 \mathrm{~h}$ after inoculation with Sclerotium rolfsii

\begin{tabular}{lll}
\hline \multirow{2}{*}{ Cultivars } & \multicolumn{2}{l}{ Total phenolic compounds ${ }^{1}\left(\mathrm{mg}^{2}\right.$ gallic acid/g DW $)$} \\
\cline { 2 - 3 } Cameroon & Control & Inoculated \\
\hline Kpodji & $3.6 \pm 0.06 \mathrm{f}$ & $26.3 \pm 0.13 \mathrm{~d}$ \\
Gboto & $3.2 \pm 0.07 \mathrm{~cd}$ & $19.8 \pm 0.07 \mathrm{c}$ \\
Sèwé & $3.5 \pm 0.02 \mathrm{ef}$ & $19.4 \pm 0.07 \mathrm{c}$ \\
Tchawé daxo & $3.3 \pm 0.07 \mathrm{de}$ & $20.4 \pm 0.08 \mathrm{c}$ \\
IT83D-326 & $3.1 \pm 0.07 \mathrm{bcd}$ & $19.4 \pm 0.08 \mathrm{c}$ \\
Delekinwa & $2.9 \pm 0.05 \mathrm{~b}$ & $14.1 \pm 0.09 \mathrm{~b}$ \\
TVU72-74 & $3 \pm 0.07 \mathrm{bc}$ & $14.3 \pm 0.12 \mathrm{~b}$ \\
KVX61-1 & $2.6 \pm 0.09 \mathrm{a}$ & $8.2 \pm 0.06 \mathrm{a}$ \\
Tchawé kpayo & $2.4 \pm 0.06 \mathrm{a}$ & $8.4 \pm 0.11 \mathrm{a}$ \\
LSD & $2.5 \pm 0.06 \mathrm{a}$ & $7.8 \pm 0.04 \mathrm{a}$ \\
$P$ & 0.2 & 4.9 \\
CV\% & 0.035 & 0.024 \\
\hline
\end{tabular}

${ }^{\mathrm{T}}$ Values are followed by the standard error. Within a column, values not followed by the same letters are significantly different $(P<0.05)$ according to the Student Newman Keuls option

equivalent/g DW were the five tolerant cultivars; the second group with total phenolic content between 14 and $15 \mathrm{mg}$ gallic acid/g DW were IT83D-326-2 and Delekinwa; the third and last group with total phenolic content less than $10 \mathrm{mg}$ gallic acid equivalent/g DW consisted of the susceptible cultivars namely TVU 72-74, KVX-61-1 and Tchawé kpayo. The tolerant cultivars had, $48 \mathrm{~h}$ after inoculation, the highest ester-bound and cell wall-bound phenolic values (Table 2). Moreover, the cell wall-bound phenolic values for all tolerant cultivars at 48 $\mathrm{h}$ after inoculation were more than eight-fold that when uninoculated (Table 2). Analytical HPLC chromatograms showed five peaks $[1(\mathrm{rt}=12.5 \mathrm{~min}) ; 2(\mathrm{rt}=17 \mathrm{~min}), 3(\mathrm{rt}=34 \mathrm{~min})$, $4(\mathrm{rt}=33.6 \mathrm{~min})$ and $5(\mathrm{rt}=37.5 \mathrm{~min})]$ at $320 \mathrm{~nm}$ corresponding to five compounds in the inoculated Cameroon cultivar samples (Fig 2A) (with strong peaks) that were absent in the non-inoculated samples (Fig. 2A and B). No difference was found between control and inoculated samples at $280 \mathrm{~nm}$. 
Table 2. Total soluble and insoluble phenolics, and their percentage compared to the total phenolic compounds in the cells of cowpea seedlings $48 \mathrm{~h}$ after inoculation with Sclerotium rolfsii

\begin{tabular}{|c|c|c|c|c|c|c|}
\hline \multirow[b]{3}{*}{ Cultivars } & \multicolumn{4}{|c|}{ Total soluble phenolics ${ }^{1}$ (mg gallic acid/g DW) } & \multirow{2}{*}{\multicolumn{2}{|c|}{$\begin{array}{c}\text { Insoluble phenolics }^{1} \text { (mg gallic acid/g DW) } \\
\text { Cell wall }\end{array}$}} \\
\hline & \multicolumn{2}{|c|}{ Free acid } & \multicolumn{2}{|c|}{ Ester-bound } & & \\
\hline & Control & inoculated & Control & Inoculated & Control & Inoculated \\
\hline Cameroon & $0.7 \pm 0.07 \mathrm{a}$ & $1.6 \pm 0.29$ a $(6.1 \%)$ & $1.2 \pm 0.31 \mathrm{a}$ & $4.3 \pm 0.28$ e $(16.3 \%)$ & $1.6 \pm 0.13 \mathrm{e}$ & $20.4 \pm 0.18 \mathrm{~d}(77.6 \%)$ \\
\hline Kpodji & $0.6 \pm 0.06 \mathrm{a}$ & $1.5 \pm 0.28$ a $(7.6 \%)$ & $1.1 \pm 0.14 \mathrm{a}$ & $3.7 \pm 0.11 \mathrm{~d}(18.7 \%)$ & $1.5 \pm 0.04 \mathrm{de}$ & $14.6 \pm 0.31 \mathrm{c}(73.7 \%)$ \\
\hline Gboto & $0.4 \pm 0.11 \mathrm{a}$ & $1.1 \pm 0.09 \mathrm{a}(5.7 \%)$ & $0.9 \pm 0.05 \mathrm{a}$ & $2.9 \pm 0.07 \mathrm{c}(14.9 \%)$ & $1.6 \pm 0.14 \mathrm{e}$ & $15.4 \pm 0.24 \mathrm{c}(79.4 \%)$ \\
\hline Sèwé & $0.7 \pm 0.34 \mathrm{a}$ & $1.0 \pm 0.04 \mathrm{a}(4.9 \%)$ & $0.8 \pm 0.09 \mathrm{a}$ & $3.1 \pm 0.04 \mathrm{c}(15.2 \%)$ & $1.3 \pm 0.13 \mathrm{bc}$ & $16.3 \pm 0.12 \mathrm{c}(79.9 \%)$ \\
\hline Tchawé daxo & $0.8 \pm 0.13 \mathrm{a}$ & $1.3 \pm 0.25$ a $(6.7 \%)$ & $1.1 \pm 0.20 \mathrm{a}$ & $3.2 \pm 0.19 \mathrm{c}(16.5 \%)$ & $1.4 \pm 0.19 \mathrm{~cd}$ & $14.9 \pm 0.17$ c $(76.8 \%)$ \\
\hline IT83D-326 & $0.7 \pm 0.16 \mathrm{a}$ & $1.1 \pm 0.05$ a $(7.8 \%)$ & $0.9 \pm 0.11 \mathrm{a}$ & $2.3 \pm 0.10 \mathrm{~b}(16.3 \%)$ & $1.3 \pm 0.08 \mathrm{~cd}$ & $10.7 \pm 0.36 \mathrm{~b}(75.9 \%)$ \\
\hline Delekinwa & $0.6 \pm 0.09 a$ & $1.2 \pm 0.22 \mathrm{a}(8.4 \%)$ & $1.1 \pm 0.15 \mathrm{a}$ & $2.2 \pm 0.23 b(15.4 \%)$ & $1.2 \pm 0.12 b$ & $10.9 \pm 0.01 \mathrm{~b}(76.2 \%)$ \\
\hline TVU72-74 & $0.5 \pm 0.06 \mathrm{a}$ & $0.7 \pm 0.17 \mathrm{a}(8.5 \%)$ & $1.0 \pm 0.19 \mathrm{a}$ & $1.7 \pm 0.04 \mathrm{a}(20.7 \%)$ & $1.0 \pm 0.12 \mathrm{a}$ & $5.8 \pm 0.09$ a $(70.7 \%)$ \\
\hline KVX61-1 & $0.7 \pm 0.03 \mathrm{a}$ & $0.8 \pm 0.02 \mathrm{a}(9.5 \%)$ & $1.0 \pm 0.24 \mathrm{a}$ & $1.4 \pm 0.32 \mathrm{a}(16.7 \%)$ & $1.0 \pm 0.06 \mathrm{a}$ & $6.2 \pm 0.09$ a $(73.8 \%)$ \\
\hline Tchawé Kpayo & $0.4 \pm 0.09 a$ & $0.8 \pm 0.11$ a $(9.0 \%)$ & $0.8 \pm 0.07 \mathrm{a}$ & $1.3 \pm 0.22 \mathrm{a}(16.7 \%)$ & $0.9 \pm 0.20 \mathrm{a}$ & $5.7 \pm 0.32$ a $(73.1 \%)$ \\
\hline LSD & 1.4 & 2.6 & 3.2 & 0.4 & 0.15 & 3.4 \\
\hline$P$ & 0.17 & 0.20 & 0.09 & 0.03 & 0.019 & 0.017 \\
\hline $\mathrm{CV}(\%)$ & 7.2 & 6.3 & 5.1 & 3.9 & 3.2 & 6.2 \\
\hline
\end{tabular}

${ }^{\mathrm{T}}$ Values are followed by the standard error. Within a column, values not followed by the same letters are significantly different $(P<0.05)$ according to the Student Newman Keuls option. Values in parenthesis within a row express the percentage of the phenolics compared to the total phenolic compounds in the stem cell. 

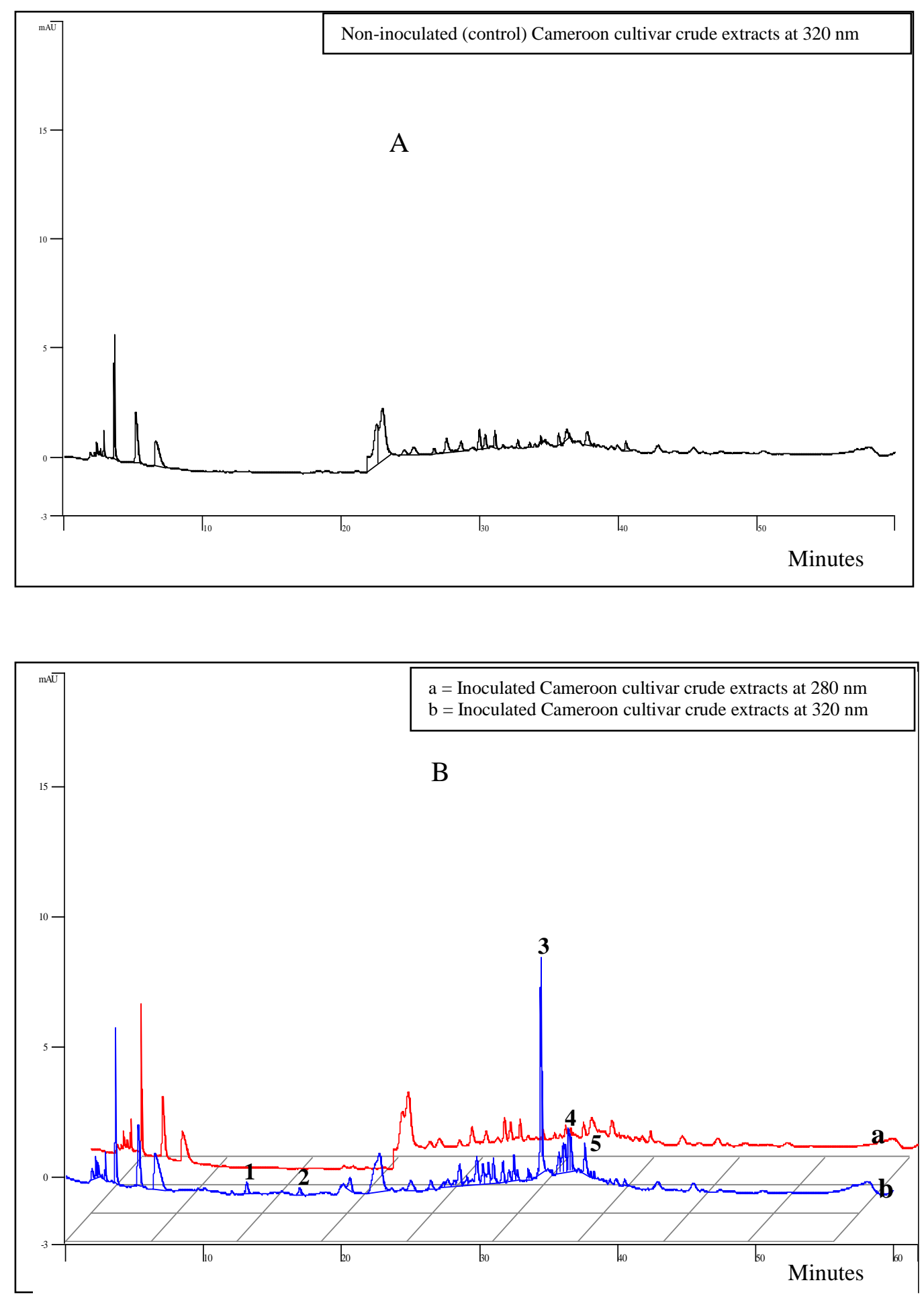

Figure 2. HPLC analysis of a crude extract of a cowpea cultivar (Cameroon) $48 \mathrm{~h}$ after inoculation with Sclerotium. rolfsii: Profile of the control sample at $280 \mathrm{~nm}$ (A), profile of the inoculated sample analysed at 280 and $320 \mathrm{~nm}$ (B). The graph b) showed five peaks that were absent in graph a): 1 (rt $=12.5 \mathrm{~min}) ; 2(\mathrm{rt}=17 \mathrm{~min}), 3(\mathrm{rt}=34 \mathrm{~min}), 4(\mathrm{rt}=33.6 \mathrm{~min})$ and $5(\mathrm{rt}=37.5 \mathrm{~min})]$.

The role of phenolic compounds in the host/pathogen interaction has been extensively reported and summarised in several review articles (Sarma et al. 2002; Maurya et al. 2007; 
Jain et al. 2011; Singh et al. 2014) and constitutive phenolics are known to confer resistance indirectly through activation of post-infection responses in the host (Harborne 1988). Several studies have shown that some phenolics are inhibitors associated with non-host resistance whereas others are formed or increased in response to pathogen infection, and are considered to be an important component in the defence response of the host to the pathogen (Nicholson and Hammerschmidt 1992). Results in the present study showed that the total phenolic compound content in the cowpea seedling stems, differed significantly $(\mathrm{P}<0.05)$ among cultivars before and increased after inoculation with $S$. rolfsii, A significant difference in total phenolic compound content was detected between the non-inoculated control and inoculated plants of the tolerant and susceptible cultivars only $24 \mathrm{~h}$ and $48 \mathrm{~h}$ after inoculation, respectively. Nandi et al. (2013) studied the hypersensitive reaction of cowpea to S. rolfsii finding that a greater accumulation of total phenol in cowpea plants was observed up to five days after inoculation. In addition, a strong relationship was observed between total phenol content and the tolerance/susceptibility status of the cultivars with the more tolerant the cultivar, the higher the phenolic content after inoculation.

The TLC analysis performed in the current study confirmed the presence of compounds belonging to the hydroxycinnamic family (data not shown). These results could indicate that, when $S$. rolfsii infects cowpea, several esters, especially cinnamic acids, are induced in the tolerant cultivars, which are able to withstand the infection caused by the pathogen. Sarma et al. (2002) also reported that phenolics including gallic, ferulic, chlorogenic and cinnamic acids were present in leaves, collar and roots of chickpea (Cicer arietinum L.) plants and the concentration increased in tolerant seedlings or was induced when plants were inoculated with $S$. rolfsii and treated with rhizobacteria. Similar results were found by Singh et al. (2014) who confirmed that accumulation of polyphenolic increases in both tolerant chickpea cultivars and microbial-treated susceptible cultivars infected by 
pathogens. Conducting research on interaction S. rolfsii-groundnut (Arachis hypogaea L.), Saraswathi and Reddy (2012) indicated that there was a tremendous increase in production of phenolic acids in the $S$. rolfsii diseased area of the groundnut hypocotyls compared to healthy ones. The authors further indicated that chromatographic data revealed 10 phenolic acids in healthy plants, whereas in the infected plants, six additional compounds were detected with the progression of the disease. In the case of susceptible cowpea cultivars, the production of a small amount of phytoalexins $48 \mathrm{~h}$ after inoculation appears to be the first attempt to stop the pathogen. However, the concentration of these phytoalexins was not sufficient to be toxic to prevent the growth of the pathogen. It was reported that resistance occurs in plants when phytoalexins reach a concentration sufficient to restrict pathogen development (Nicholson and Hammerschmidt 1992; Kuć 1995) whereas formation of phytoalexins in a susceptible host following infection by a pathogen seems to be prevented by suppressor molecules produced by the pathogen (Bailey and Mansfield 1982). In our current study, two phytoalexins revealed by the HPLC analysis might be produced by the cowpea tolerant cultivar seedlings in response to $S$. rolfsii infection.

The content of soluble free acid found in the stem did not vary over cultivars, though it increased $48 \mathrm{~h}$ after inoculation. The low percentage of metabolites found in the stem is similar to previous data reported in wheat (Triticum turgidum L.) (Regnier 1994). This low increase of free acid content in the stem after inoculation by the pathogen is not unusual and can be explained by the orientation of the metabolism to the esterification of these acids and further to an integration of the phenolics into the cell wall in order to protect the plant cells against the invasion (Fry 1979). After inoculation, the ester-bound and cell wall-bound phenolics were induced more than 1.5- and 8-fold, respectively, compared to the controls. These data are consistent with early reports on other crops (Regnier 1994; Chen et al. 2000; Mohammadi and Kazemi 2002) and accumulation of lignin and phenolic compounds in the 
host, in response to fungal attack is well known for strengthening the cell wall. The results in the present study showed phenolic compound, mainly ester-bound soluble and cell wallbound phenolics are the major phenolics in cowpea cultivars involved in the tolerance of the plant against damping-off and stem of cowpea caused by S. rolfsii. These preliminary results show that phenolics present before and after $S$. rolfsii infection, could be used as screening parameters for tolerance to $S$. rolfsii damping-off and stem rot. Further research may provide more information on the characterisation and purification of the phytoalexins involved in the tolerance.

\section{Acknowledgements}

The authors would like to thank the National Research Foundation, South Africa, for their financial support.

\section{Literature cited}

Adandonon, A., Aveling, T. A. S., Labuschagne, N., \& Ahohuendo, B. C. (2005a). Etiology of and effect of environmental factors on damping-off and stem rot of cowpea in Benin. Phytoparasitica, 33, 65-72.

Adandonon, A., Aveling, T. A. S., \& Tamo M. (2005b). A new laboratory technique for rapid screening of cowpea cultivars for resistance to damping-off and stem rot caused by Sclerotium rolfsii. International Edible Legume Conference in conjunction with IV World Cowpea Congress, 17 - 21 April 2005, Durban, South Africa.

Aveling, T. A. S., \& Powell, A. A. (2005). Effect of seed storage and seed coat pigmentation on susceptibility of cowpeas to pre-emergence damping-off. Seed Science and Technology, $33(2), 461-470$ 
Basha, E., Friedrich, K. L. \& Vierling, E. (2006). The N-terminal arm of small heat shock proteins is important for both chaperone activity and substrate specificity. Journal of Biological Chemistry, 281, 39943-39952.

Bailey, J. A., \& Mansfield, J. W. (1982). Phytoalexins. Wiley, New York.

Chen, C. Q., Belanger, R. R., Benhamou, N., \& Paulitz, T. C. (2000). Defense enzymes induced in cucumber roots by treatment with plant growth-promoting rhizobacteria (PGPR) and Pythium aphanidermatum. Physiological and Molecular Plant Pathology, 56, 13-23.

Du Plooy W., Regnier T., Combrinck S. (2009). Essential oil amended coatings as alternatives to synthetic fungicides in citrus postharvest management. Postharvest Biology and Technology, 53, 117-122.

Fry, S. C. (1979). Phenolic components of the primary cell wall and their possible role in the hormonal regulation of growth. Planta, 146, 343-351.

Harborne, J. B. (1988). Introduction to Ecological Biochemistry. Third edition. Academic Press, London.

Jain, A., Singh, S., Sarma, B. K., \& Singh, H. B. (2011). Microbial consortium-mediated reprogramming of defense network in pea to enhance tolerance against Sclerotinia sclerotiorum. Journal of Applied Microbiology, 112, 537-550.

Kritzinger, Q., Aveling, T. A. S., \& Marasas, W. F. O. (2002). Effect of essential plant oils on storage fungi, germination and emergence of cowpea seeds. Seed Science and Technology, 30(3), 609-619.

Kuć, J. (1995). Phytoalexins, stress metabolic, and disease resistance in plants. Annual Review of Phytopathology, 33, 275-297.

Maurya, S., Singh, R., Singh, D. P., Singh, H. B., Srivastava, J. S., \& Singh, U. P. (2007). Phenolic compounds of Sorghum vulgare in response to Sclerotium rolfsii infection. Journal of Plant Interaction, 2, 25-29. 
Mohammadi, M., \& Kazemi, H. (2002). Changes in peroxidase and polyphenol activity in susceptible and resistant wheat heads inoculated with Fusarium graminearum and induced resistance. Plant Sciences, 162,491-498.

Morrissey, J. P., \& Osbourn A. E. (1999). Fungal resistance to plant antibiotics as a mechanism of pathogenesis. Microbiology and Molecular Biology Reviews, 63(3), 708-724.

Nandi, S., Dutta, S., Mondal, A., Adhikari, A., Nath, R., Chattopadhaya, A., \& Chaudhuri, S. (2013). Biochemical responses during the pathogenesis of Sclerotium rolfsii on cowpea. African Journal Biotechnology, 12, 3968-3977.

Nicholson, R. L., \& Hammerschmidt, R. (1992). Phenolic compounds and their role in disease resistance. Annual Review of Phytopathology, 30, 369-389.

Pakela, Y. P. (2003). Interaction between Colletotrichum dematium and cowpea. PhD thesis, University of Pretoria, Pretoria.

Regnier, T. (1994). Les composés phénoliques du blé dur (Triticum turgidum L. var. durum): Variations au cours du développement et de la maturation du grain, relations avec l'apparition de la moucheture. Thèse de Doctorat d'Etat. Université Montpellier II, France.

Saraswathi, M., \& Reddy, M. N. (2012). Phenolic acids associated with Sclerotium rolfsii in groundnut (Arachis hypogaea L.) during pathogenesis. International Journal of Plant Pathology, 3, 82-88.

Sarma, B. K., Singh, D. P., Mehta, S., Singh, H. B., \& Singh, U. P. (2002). Plant growthpromoting rhizobacteria-elicited alterations in phenolic profile of chickpea (Cicer arietinum) infected by Sclerotium rolfsii. Journal of Phytopathology, 150, 277-282.

Singh, A., Jain, A., Sarma, B. K., Upadhyaya, R. S., \& Singh, H. B. (2014). Rhizosphere competent microbial consortium mediates rapid changes in phenolic profiles in chickpea during Sclerotium rolfsii infection. Microbiological Research, 169, 353-360. 